\title{
Why you need to include human factors in clinical and empirical studies of in vitro point of care devices? Review and future perspectives
}

\section{Simone Borsci, Peter Buckle \& George B. Hanna}

To cite this article: Simone Borsci, Peter Buckle \& George B. Hanna (2016): Why you need to include human factors in clinical and empirical studies of in vitro point of care devices? Review and future perspectives, Expert Review of Medical Devices, DOI: $10.1586 / 17434440.2016 .1154277$

To link to this article: http://dx.doi.org/10.1586/17434440.2016.1154277

Accepted author version posted online: 15 Feb 2016.

Submit your article to this journal

Ш Article views: 3

View related articles $\sqsubset$

View Crossmark data $\nearrow$ 
Publisher: Taylor \& Francis

Journal: Expert Review of Medical Devices

DOI: $10.1586 / 17434440.2016 .1154277$

\title{
Why you need to include human factors in clinical and empirical studies of in vitro point of care devices? Review and future perspectives
}

\author{
Simone Borsci*, Peter Buckle, George B. Hanna
}

Imperial College, London, National Institute for Health Research Diagnostic Evidence Cooperative of London.*Author for correspondence: $\underline{\text { s.borsci@imperial.ac.uk }}$

\begin{abstract}
Use of in-vitro point of care devices - intended as tests performed out of laboratories and near patient - is increasing in clinical environments. International standards indicate that interaction assessment should not end after the product release, yet human factors methods are frequently not included in clinical and empirical studies of these devices. Whilst the literature confirms some advantages of bed-side tests compared to those in laboratories there is a lack of knowledge of the risks associated with their use. This article provides a review of approaches applied by clinical researchers to model the use of in-vitro testing. Results suggest that only a few studies have explored human factor approaches. Furthermore, when researchers investigated peopledevice interaction these were predominantly limited to qualitative and not standardised approaches. The methodological failings and limitations of these studies, identified by us, demonstrate the growing need to integrate human factors methods in the medical field.
\end{abstract}

Keywords: Acceptance, Clinical Studies, Ergonomics, Human Factors, In Vitro Test, Interaction, Point-of-care, POC, Satisfaction, Usability, 


\section{Introduction}

In vitro point of care (POC) testing are medical tools generally designed to be used near patient, or outside the traditional laboratory environment to rapidly inform diagnostic and clinical decisions [1-3]. Nowadays, a number of POC devices are used for a range of testing in clinical and home environments [4]. In 2013 the POC market was estimated to be $\$ 54$ billion - i.e., 15\% of the overall medical device market [5]. Evidence showed that the popularity of POC devices is linked to the fact that clinicians can save time and costs by rapidly, and comfortably testing people $[4,6]$, thus increasing both patient's satisfaction and clinician's decision-making [7].

Moreover, POC tools are generally seen as a way to facilitate the self-management of chronic conditions, to improve the clinician-patient relationships [6], and to help patients comply with therapies [8]. Clinical experts are used to explore and assess the sensitivity and specificity of the POC devices in the real context of use, and including qualitative assessment of the acceptance and satisfaction of clinicians and patients $[4,6,9,10]$. Whilst significant concerns about the acceptance, usefulness, reliability and safety of the interaction with POC are clearly expressed in literature $[6,8]$, these human factors variables are too often considered as only secondary aspects with an assumption that they have only a minimal impact on the device functioning and use.

Gurses et al [11] identified that healthcare professionals and researchers are not fully aware of the methods and principles of human factors and ergonomics (HFE). HFE is the multidisciplinary science in which human behaviour, capacities and engineering principles are used to explore why errors occur, and how to reduce the likelihood of preventable harm to individuals, with the specific aim to support human performance and safety [12]. Professionals in the medical field are more likely to be focussed on enhancing diagnostic decision making, and on the comparison of POC devices with laboratory testing. Thus, medical studies have rarely looked at aspects such as the effect of user errors on decision making, or the effect of design issues on the safety in use and the reliability of a device.

This lack of inclusion of HFE perspective in clinical studies may be due to the fact that healthcare professionals assume the devices are usable and safe because these tools are already available on the market, or because manufacturers, before the release, should have performed a full range of HFE analysis to verify and validate the device in keeping with international standards [13,14]. However, given the complexity of medical field $100 \%$ error free devices are not achievable [15] and the available data on product adverts events and medical recalls show that medical devices on the market may suffer from severe design issues that strongly affect diagnostic decisions and patient safety. For instance, in 2012 in the UK 13,549 patients were involved in device induced adverts events due to faulty system and human errors [16]. These events produced 305 fatal incidents and 4,417 serious injuries. Concurrently, recent data from USA suggested that, in $2014,40 \%$ of the devices recalled from the market for safety reasons were affected by issues related to labelling, packaging and software functioning [17].

As these data on device recalls and adverse events show clinicians and researchers, need to consider how to check both their interaction with the product (e.g., time and errors in use,) and also how patients react and perceive the product. Both are needed to fully assess the reliability of a POC device. Such is the variability of context of use and range of users that this will be necessary even when the manufacturer have provided reliable evidence that a device is well designed and safe.

The current limited application of HFE approaches in clinical and comparative studies results in a limited knowledge of how much POC devices may be bringing medical errors closer to the 
patients [18]. Recently researchers have investigated the interaction issues associated with POC devices by modelling the characteristics and error in the use of these devices [18,19]. Yet there is still a lack of inclusion in health studies of the methods and approaches required to assess HFE variables and to control the interaction with the devices in the field.

When HFE approaches have been applied in the healthcare field positive results were achieved in enhancement of interaction with the device, patient safety, situation awareness and communication between clinicians and patients [see, for a review: 11,20]. Despite this there remains a gap between the medical field and other high-risk industries in the integration of HFE methods into healthcare practice $[11,12,21]$. This may in part be due to the fact that health professionals, without expertise or support of experts on HFE, are often asked to explore the usefulness of devices and/or to prevent and report device induced adverse events in the field [22].

\section{Human factors in medical field}

Lessons learned in healthcare field about errors show that human errors and adverse events in medicine are problems of human behaviour, capacities and engineering, not of medicine [23]. This does not means that health professionals do not have to deal with errors, but rather that medical experts need the assistance of HFE to avoid adverse events, to deal with errors, and to optimise the relationship between humans and devices in the context of use.

HFE professionals in a healthcare environment may observe human behaviour, abilities, attitudes and limitations, and use these data to assess devices, to aid new design and, where necessary, to inform the redesign the broader sociotechnical systems and define the practices of use to enhance safety [24].

Errors (i.e. any failure to perform an intended action that was correct given the circumstances [23]) may arise in a variety of ways in those complex sociotechnical environments where operators with different skills are required to use technologies. Each sociotechnical context can be characterized by specific workflows, culture, rules and constraints of communication, social interactions and a set of technologies. Due to their portability POC devices can be used in different contexts - e.g., from the clinical wards, triage centres, doctors' ambulatory, to the home or in daily contexts of patients. These multiple environments of use, imply multiple end-users of the device with different expertise and roles, thus concurrently increasing the possibility of unsafe use and adverse events. Therefore, when an error does occur, the blaming of operators, users or manufacturers for that is generally an inappropriate and misleading concept [25]. Error could happen to anybody for many reasons, such as errors induced by poor design, unseen device faults, unsafe actions, lack of experience or training etc. However, errors in design or in the use of a device in addition to any unsafe and not well-planned practice may lead professionals to miss-diagnosis or to wrong diagnostic processes and expose patients to risks.

HFE, particularly in health care, aims both to identify and model the possibility of errors and to support mitigation strategies. Evidence in the health care literature supports the idea that macroergonomics approaches [11,12,20] - intended as the HFE applied to the work system design [26] - are appropriate practices in the medical field. Macro-ergonomics, by exploring the current practices in sociotechnical environments, serves the scope to improve the healthcare processes, 
by reducing the likelihood of errors, time wasting and thereby enhance the service which in turn generates a positive experience for patients and their caregivers.

An example of 'macro-ergonomics' are those system approaches which aim to model, observe and enhance the healthcare work environments, the contextual interactions, and healthcare quality and patient safety $[21,27,28]$. Concurrently HFE can be used by health professionals and administrators to map the device use - i.e., system mapping [29] - and to visually model the health care processes [30] to identify previously unrecognised opportunities in the context to improve patient safety, to define better care practices and to properly define the use of devices [31].

Moreover, other HFE approaches for complex systems analysis can be applied to explore the healthcare sociotechnical system at a macro level, such as cognitive work analysis[32], work domain analysis [33], and hierarchical task analysis [34]. The holistic perspective of macroergonomics, however, has to be integrated [35-37] with all those methods that aim to investigate people interactions with technologies at a micro (i.e., individual) level.

Macro-ergonomics studies have an established place in enhancing the health care processes in terms of safety and use of the devices from organizational level whilst micro-ergonomics analyses, that mostly aim to observe in detail the interaction and the safety in use of devices at an individual level, are minimally performed in the field.

Experts in HFE are increasingly looking to methods and frameworks to understand the relationships among micro-ergonomic variables (e.g.) usability of a product, people reaction, satisfaction), and the rules and constraints of the health sociotechnical contexts usually studied at macro-ergonomics levels [38].

Error-prone devices applied in safe and well-designed care process may introduce bias in the clinical outcomes - i.e., issues at micro-level may affect the larger 'macro' system. Alternatively, a poorly designed sociotechnical system may affect the performances in use of an, otherwise safe and usable, medical device thus comprising the delivery of healthcare - i.e., issues at macro-level may affect the micro one.

In light of this, any interaction assessment has to include device evaluation in medical practice to fully understand and/or model the device use. This inclusion of HFE assessment in field studies is also supported by the ISO 62366 [13] that clearly outlines that the evaluation of interaction and use of medical devices cannot end once that the technology is available in the market.

The variables required to assess the interaction are largely studied in other industry fields automotive, aviation etc. [see, for a review: 39] - to observe and to identify unseen risks of use and possible miss-use induced by a wrong design. A full assessment of interaction, in tune with literature and standards [13,14,38-43] may include key variables, such as:

Acceptance of the device use. In line with the technology acceptance model [44,45] people's decision to use or not use a device and their subsequent behaviour in use is affected by several factors. These include: i) perceived usefulness, ii) ease of use, and iii) attitude towards a device. Together with these factors, the evidence suggests that previous beliefs $[46,47]$, as well as, their preference and experience with similar technology [48-50] may affect interaction by acting as a barrier or a facilitator to use. Acceptance, and it's main variables, can be measured through well establish scales [44]. In HFE studies acceptance measures (i.e., perceived usefulness and attitudes toward the device) are also part of the assessment of 
people expectations and reaction to the interaction, and are related to the evaluation of the satisfaction in use and user experience [48-50].

- Usability. This is defined as effectiveness, efficiency and satisfaction of product usage in the specific context [42]. Usually, after a preliminary expert analysis of risk in use and simulations [13], usability is assessed through end-users tests to observe people performances and errors in use. Afterwards, users are asked to fill standardised satisfaction scales to gather data about the perceived usability of the tool.

- User experience. This is defined as a person's perceptions and responses that result from the use or anticipated use of a product, system or service [43]. This is a broad concept that includes and extends the usability assessment. User experience is measured through the time, and include the analysis of people performance, their satisfaction and attitudes already included in the acceptance and usability assessment - but also the assessment of people preference, their emotional and physiological reaction to the aesthetics and the functioning of the product, as well as intention to use and the likelihood of promoting the product to colleagues. A wide set of methods [see, for a review: 51,52] can be applied to perform expert analysis of the device and observe effectiveness and efficiency of the interaction by testing performances in use (time, errors in use and achievement of tasks) and by also modelling the impact of previous abilities and skills. Moreover, well tested scales can be applied to assess user satisfaction [e.g., 53], intention to use, and experience in terms of expectations, reactions and preferences [e.g., 48,49,54].

- Expectations before the device use and people reaction to the device during and after the use. Physiological reaction assessments are well established in HFE [for a review, see: 39], and usually test specific biofeedback technologies, or assess aspects such as the cognitive workload in the use of a device [e.g., see: NASA-Task Load Index instrument: 55]. Concurrently expectations may be assessed through quick scales [49,50] to capture pre- and post-use concerns and needs preferences These expectations strongly related to satisfaction of use, perceived usefulness, aesthetics and experience with the product $[49,50]$ thus providing useful insights about the usability, intention of use, attitudes and acceptance of the product [48].

Each one of these aspects is related to the others. Therefore, for instance, the assessment of user experience includes variables which are important also for the acceptance evaluation and vice versa. All the variables for the assessment are usually gathered through a very specific set of methods - such as verbal protocols, observation, scenario base analysis, task analysis- and wellestablished evaluation scales [21,38-40]. Researchers may decide to extend the assessment by exploring a larger set of variables but, time constrains and costs usually limit these when measuring one or more aspects of the user's interaction with a tool (Table 1).

\section{[TABLE 1 ABOUT HERE]}

This paper has selected and reviewed published studies that observed at least one interaction target measure. This survey of the literature aims to assess which:

i) HFE aspects are currently explored in the healthcare studies on the use of POC

ii) methods are applied to assess the target measure

iii) variables are or are not considered in the medical field 


\section{Current clinicians' perspective on interactive issues with POC devices}

To obtain an overall picture of the number of studies on POC devices, titles of journal and conference papers in PUBMED were searched with a set of keywords (see annex 1) applied in previous reviews [6,56]. This resulted in a set of 2,015 articles published 2000 to 2014, with publications increasing significantly over the period (see, Fig 1).

[FIGURE 1 ABOUT HERE]

Researchers have increasingly focused their attention on POC devices because these are considered the most reliable line of diagnostic technologies future development [57]. In literature, some work was done to control the interaction quality with interfaces of compater based POC tools [58,59]. Nevertheless, to our knowledge, no studies looked at the oyerall interaction with the physical device and its emended software. In tune with that, professionals raised several concerns and issues $[4,6,60,61]$ related to marginally explored $H F E$ aspects in the use and interaction of POC devices. Below we will discuss the issues reported in literature in terms of key HFE aspects of interaction assessment listed as follow: Acceptance, Usability and experience, and expectation and reactions.

\section{Acceptance}

Researchers identified concerns associated with attitudes, perceived usefulness and ease of use of POC devices. For example, when clinicians choose between POC testing and laboratory tests [6] they usually prefer to perform their diagnosis through the latter, or to double check POC outcomes with those from the laboratory [8]. This is because POC devices are, by their nature, tests performed in a less controlled environments and thereby potentially less accurate, than laboratory tests [8].

Whilst the attitudes of general clinicians is to rely on POC outcomes, health care managers often express the concern that in future clinicians may over-rely on these devices [60]. This concern is around the potential for an increase in false-positive outcomes, leading to inappropriate diagnosis and treatments $[6,8]$. Although, qualitative data on acceptance are available in literature, in empirical studies of POC devices researchers usually gather data on only one index: the rate of acceptance of patients having (or clinicians using) a POC test [e.g., see: 62,63-65]. Although valuable, this does not inform researchers about the factors associated with acceptance - i.e., attitudes, usefulness, easiness of use. It is essential to understand these to assess whether or not the end-users (clinicians or patients) are going to use the device in future. For instance, patients and clinicians who accepted the use of a new POC device may, after a bad experience, decide to not use any more that rapid tests in the future. Similarly, a device with a high rate of acceptance, may then face barriers when it has to be adopted in the clinical practice due to unexplored issues in the users (patients and clinicians) experience with the device.

\section{Usability and user experience.}

Clinicians know the importance of usability for the quality of the POC use [66], and evidence shows that errors in use, as well as error in design could produce inaccurate results leading to inappropriate treatments [58]. Although the FDA [67] in the United States of America suggested that, when it is necessary, these kinds of interaction assessments can be included in clinical 
studies, to date there are no available data in the literature about their inclusion in POC studies carried out in the field of usability and user experience methods. In tune with literature clinicians and patients satisfaction in use, perceived usefulness of POC devices and interaction with devices is not yet fully explored in clinical studies $[4,6]$.

\section{Expectations and reactions}

Evidence suggests $[4,6]$ that POC devices are considered limited tools that can be used only in certain situations and with specific patients, or to deliver very limited diagnostic actions. Moreover, devices often appear problematic in terms of their functions and aesthetics even before use. Researchers have found that only a minimal proportion of portable POC device on the market are interoperable [19] and professionals could face several restrictions in terms of data exchange and integration due to different and not compatible formats. Moreover, professionals often reveal that the time needed, the time constraints and/or the lack of functionalities associated with the use of POC tools could create issues (stress, workload, frustration) for both clinicians and patients $[68,69]$. Nevertheless, preferences before use (expectations) and after use (reactions) as well as the induced stress or workload may affect the overall experience with a device, as well as the attitudes and the acceptance of the tools.

\section{Methods}

To explore the current application of HFE methods to assess the interaction with POC devices in the clinical and empirical studies we combined, through Boolean operators (AND / OR), the keywords related to POC devices (Annex 1) with a set of HFE keywords coming from: ISO 62336 [13], the standard definition of usability [42] and user experience [43], and from OVID and IEEEXPLORE thesaurus (see Annex 2). We used these two set of keywords to scan both the title and the abstract of conference and journal papers published from 2000 to 2014 available in the following databases: PUBMED, OVID, IEEEXPLORE, and SCOPUS. One-hundred and fifty-nine articles were identified from this research. We excluded all the studies that did not present, or discuss methods and tools for the assessment of factors related to the interaction and use of products. Moreover we excluded studies focused only on usability assessment of software or computer based solutions for clinical decision making. Whereas, we included empirical studies carried out in medical field in which researchers, aiming at empirically explore or compare POC devices, also assessed one or more of the following three aspects of interactions: i) acceptance, ii) usability and experience, and iii) expectations and reaction to the device.

\section{Results}

\section{Literature search}

Among the sample of 2,015 references, only 7.8\% (159) directly refers to HFE aspects. After removing four duplicate citations, title and abstract screening excluded 18 and 41 articles, respectively. These were excluded because references were related to studies on software and interface inspections of device, or to POC devices in which the researcher explored only reported data about use or acceptance rate of the device without further investigation of these HFE aspects [e.g., see: 70,71]. Moreover, applying the pre-defined full text eligibility criteria to 
the remaining references, 19 relevant articles were included. The process is described in detail in Figure 2.

\section{[FIGURE 2 ABOUT HERE]}

\section{Characteristics of the selected studies}

Among the 19 included studies (see Table 2), 42.1\% discussed POC for HIV [62-64,70-76], $57.9 \%$ discussed the use of POC devices for other diseases - e.g., diabetes, myocardial infraction etc. - or the attitudes toward the POC technologies in the field $[7,59,60,65,68,77-85] .52 .7 \%$ of the papers explored variables related to the analysis of performance, usability and experience in use, while $47.3 \%$ explored concepts related to the acceptance and attitude in use of POC device. Only in two studies (see Table 2) did researchers also explore variables related to expectations and reactions to the POC device [75,84]. Only $26.3 \%$ of the studies involved both patients and professionals, $42.1 \%$ of the studies only gathered patients' perspective, and $31.6 \%$ only surveyed health professionals. Participant sample sizes of the reviewed articles varied greatly. Laurence et al. 2010 [7] involved 4968 patients, while Seto et al. 2006 [83] included only 4 health professionals. The number of participants was less than 100 in three studies, between 100 to less than 1000 in twelve cases, and over 1000 participants in four studies.

\section{[TABLE 2 ABOUT HERE]}

\section{Applied methodologies to assess human factors and ergonomics aspects}

Seventeen out of nineteen studies applied a questionnaire alone, or associated to methods such as interviews or observations, while in the remaining studies participant's experience after the device use was investigated through an interview. Although many studies were carried out by questionnaires, none of the reviewed studies referenced a validated instrument, or built assessment scales on the basis of available questionnaires in literature. Moreover, only in 7 of the 19 cases were the set of questions applied in the study made available $[7,64,65,68,74,75,83]$.

Researchers were varied in their approach to the three interaction aspects, and in the $84.3 \%$ of the cases (see table 3) they failed to collect all the data needed to fully report on the target measure. In our database (see table 2):

(i) Researchers who aimed to measure acceptance are mainly focussing on the overall rate of acceptance of the device use as a "one-measure-fits-all" solution. Acceptance rate is usually measured in terms of the number of people who accept or decline to use the test [e.g., see: $63,64,65,76,82,84]$, or as the number of clinicians who use or would like to use a rapid test instead, or together with, a lab test [62,72]. Moreover, to explore the reasons behind the acceptance, researchers often applied statistical analysis to control the effect of people's characteristics and skills on the overall rate of acceptance. Concurrent questionnaires and interview were applied to explore patients and professionals' attitudes towards the test and the possible barriers for the device use. No one of the studies, however, gathered data on ease of use and only in one case was the usefulness of the rapid test explored [82]. From the HFE point of view, acceptance factors - i.e., 
usefulness, easiness of use and attitudes with the device - were only partially investigated in our dataset of POC studies.

(ii) Only in one case [68] was experience measured by multiple assessment points to assess the experience gained after a sustained period of usage - e.g. after three months. While only in four cases $[68,79,80,83]$ did researchers directly gather data about people performance - in terms of time, and errors in use/reading the results etc. This is a key step to measure efficacy and effectiveness dimensions of usability [42]. Satisfaction in use, which is the third metric of the usability, was measured in six studies $[7,68,74,76,80,82,83]$. However, only three of these studies $[68,80,83]$ considered all the necessary factors to enable a satisfactory report about the usability of the device, while all other studies have measured, predominantly, the perceived use, usefulness or satisfaction in use of the device.

(iii) Expectations and reactions variables were marginally included in two studies $[75,84]$ in which researchers, by aiming to assess the acceptance and comparison of different versions of a device, also gathered data through scales, about people preferences after the use of the device.

\section{[TABLE 3 ABOUT HERE]}

\section{Discussion}

This review has found a general lack of common and validated scales to measure HFE related variables in studies on POC devices. This is surprising as HFE methods, and interaction variables are well established across different industries. Moreover reliable scales are available to measure interaction factors. Howeyer, researchers on POC device have usually applied unvalidated scales that are often shaped for their specific objectives. This means that it is hard to reliably compare the findings from each study because some key factors are missing or have been evaluated with a different set of questions or with different approaches. Moreover in several cases the set of questions and scales are not presented or discussed in the articles, thus reducing the scope for comparative assessment.

Our data showed that, although the rate of acceptance and the analysis of the effect of people characteristics on this rate are commonplace indicators in POC device, key aspects to fully explore the acceptance are often left unexplored. Conversely, studies that aim to assess usability and user experience with devices, generally gather enough data about user performance, with direct or indirect observation methods. However, even where this does happen researchers do not apply standardized scales to assess variables such as user satisfaction, perceived usefulness or likelihood of use. Also, expectations and reactions to the device, which are commonly measured in HFE studies $[48,49]$, are often unexplored or only marginally analysed through qualitative questions about preferences after use.

Our review has shown that clinical researchers have started to explore more HFE variables (11 of the 19 studies were produced after 2009) but that these variables are generally only partially assessed in POC device studies. Moreover, a serious concern can be raised about the POC studies in the dataset, namely the lack of a holistic perspective on the people-device interaction assessment. As Stricklin and Struk [59] pointed out, POC device system functionalities will require continual adjustments, because integration in the context of use is an ongoing process, 
and HFE is a main component of a successful implementation of POC technology in a complex sociotechnical setting, such as healthcare. Much of what we found was far removed from this sociotechnical approach. Often the studies assumed the device as usable without even testing the use of the tool in the context of use through an expert review (e.g., task analysis, cognitive walkthrough etc. $[40,41])$ or by a simulation of use through small pre-experimental group of operators. Therefore, acceptance studies (see Table 1) gather no insights about the effect of design errors, or user errors during the manipulation of the device on patients or insights into the clinicians' attitudes toward the tool. Similarly, usability or experience studies do not report any information about previous expert analysis or studies on the devices, nor available manufacturers' data on the usability of the tool.

The lack of HFE approaches in POC studies strongly suggests, along with the findings of others $[11,12,24,35]$, that the diffusion of HFE know-how in medicine could potentially generate new or enhanced evaluation paradigms to fully assess micro- and macro-ergonomics aspects of device interaction. This would help researchers to gather, through standardize and comparable scales, a fuller perspective on POC use and potential safety issues. Moreover, the holistic perspective embedded in HFE approaches may act as a proxy in the clinical field studies on POC and medical device to produce valuable insights that could lead to reduce 'device recalls' and induced adverse events.

Potential users of the evidence retrieved should notice that studies have heterogeneous aims and highly variable numbers of participants (clinicians and patients). Despite this limitation, the current study provides both a comprehensive review of the current methods to survey HFE related variable in POC devices studies, and the current lacks in these studies.

\section{Expert commentary}

An increasing request of HFE contribution in the medical field is required in the literature $[11,12,21,38]$. However, we have found that HFE are partially or not applied in the clinical field, and often there is a lack of expertise to identify and properly assess the key variables of the interactions with and use of POC devices. This limited application HFE in the medical field could be due to myths and previous beliefs about HFE [12]. This must be addressed as there are at least three main advantages in the inclusion of HFE in the design of clinical and empirical studies on POC. These are:

(i) By using well-established psychometric tools and validated scales, HFE experts may bring to medical field an effective way to compare and communicate their results on the use of POC devices, make replication of studies and evaluations easier, and facilitate reporting. (This is because researchers need only list the name of the questionnaire rather than reporting, in full, the development and content of, for example, a 'home grown' questionnaire [86]. )

(ii) HFE knowledge about the interaction with technologies brings a holistic perspective [59] to the medical field and generates important insights a) for those with responsibility for hospital procurement, b) for clinicians on how to use a POC device, c) about safety issues associated with the device, d) for reducing barriers of use across different wards and hospitals and e) for enhancing the level of acceptance of a new device for both clinicians and patients. 
(iii) HFE expertise and knowledge may play a key role for extending and including new variables in clinical studies. For instance, to our knowledge, no studies are available in the literature on the "trust", when in use, of a POC device. Trust in use is an emerging concept in the HFE field that is evaluated through a set of questions administrated before and after the use of a tool [46]. Trust is a measure of people's beliefs towards a technology based on previous experience with similar devices that is strongly related to the acceptance. In fact, previous experience can generate a set of general belief, which may affect both people's decision to use and attitudes toward a set of technologies or processes. For instance, a low level of trust in a set of products (general trust) may affect the trust in the use of a specific product (specific trust), thus decreasing the intention to use that product. However, trust is a dynamic concept and people can revise their previous belief. For instance some evidence, from the automotive field [47], shows that, independently from the initial general trust to a group of products/technology, products with a good level of usability may positively reshape people's trust in the use of a specific product.

In keeping with Kost's concept of POC culture $[87,88]$ people are today increasingly empowered by POC tools and they are developing skills to care for themselves through innovative technologies. This generates new and contextual forms of medical practices as well as new norms, behaviours, beliefs, attitudes and expectations toward devices. The POC culture varies from country to country, and different sociological and cultural factors affect the use (and the diffusion) of POC in different environments [89-92]. Unfortunately, this growing culture, is not yet aligned with our scientific knowledge of the key factors affecting the overall interaction and experience with devices. In fact, as we have shown in this article, factors - such as usability, experience of use, safety, satisfaction, expectation, attitudes and acceptance - are only marginally explored in the field, and are often reduced to simulation of use tests. These are usually with a small sample of users in laboratory environments or through the use of qualitative questionnaires with limited scope for comparison of results. HFE experts should embrace the concept of POC culture, and then promote clinical trials and analyses in the field of POC using standardised, rigorous approaches to enable scientific communities to explore and compare the multiple factors behind the safe and effective use of devices in differing cultural contexts and environments.

\section{Five-year view}

POC devices are considered a paradigm-shift in global healthcare [93]. These technologies are constantly evolving as tools to support home care, evidence-based personalized care, patient centred medicine, and preventive healthcare. In the future there will be a growing need to ensure the safety and the usability of these devices used both in hospitals and in the home $[18,59,93]$, and to functionally integrate such technologies with the medical practices and contexts of use.

The growing diffusion of POC devices is a direct result of the advancements in chemistry, materials and manufacturing. In the near future, advancements in manufacturing, tailoring process, materials and research in biomarkers and compounds will allow industries to produce cheaper devices, more integrated with the clinical field, with high levels of both specificity and sensitivity and with great levels of interoperability thus increasing the diagnostic answer and the 
usefulness of POC tools. In all of this HFE will play a small part. We contend that, as happened for many other industrial products (e.g. such as mobile phones, tablets, computers etc.) HFE must play a key role in anticipating, understanding and avoiding current and future barriers in the effective and safe use of POC technology. The main contribution of HFE expertise integrated in the device development process and in the clinical studies will be to help manufacturers and clinicians to shape, revise and properly use the products. This will be achieved in keeping with end-users expectations and needs by minimizing the risks, enhancing the safety in use and ensuring that future integrated POC technologies conform to HF design principles [94]. In fact, the more POC devices become easy to use and diffused, then the more these technologies will weave themselves into the fabric of everyday life until they will be indistinguishable from other technologies [94]. The process of technology 'disappearance' has already started with POC tools that are, for instance, available and integrated into mobile applications (e.g., see: http://www.thyrometrix.com/; or http://www.colorimetrix.com/). Therefore, we are in the middle of an extraordinary evolution of the healthcare technologies, and HFE is a catalyst to the POC diffusion, use and enhancement [95] that will support manufactures and medical professionals in handling the future.

POC technologies will become portable, faster and smarter. Probably, patients in the near future will receive not only the clinical results through POC systems, but they will also be required to use under skin sensors to: i) monitor their well-being over a time period, ii) communicate online with clinicians. Feedbacks to patients through smartphone technology is highly probable.

While the medical field is rapidly progressing from the technological point of view, the methodological assessment of patient-clinicians interaction with devices has much to do. It is still far from achieving an integrated approach that could consider key aspects such as expectations (before and after the use), the context of use, cultural differences, and the end-user experience.

HFE experts need to encourage developers and clinicians to utilise rigorous, scientific usability methods. There may also be a need to assess emotional reactions to measure explicit and implicit reactions during the interaction with a device. Such assessments may be achieved through biofeedback and algorithms to track facial expression, measure cognitive workload etc. [39]

A holistic and well-integrated assessment of people experience with POC devices in the field will support and extend our understanding of patients and clinicians needs, errors of use and the barriers to adopting a product.

An effective and efficient interaction is affected by several factors, therefore, a well-designed device experienced by people and clinicians in UK could have very differently reaction with users in other cultural settings where patients and clinicians may have different needs, expectations, habits and attitudes. Therefore, not only must usability and safety be considered by experts (to avoid miss-use and errors), but also the overall experience that supports the use and the acceptance of devices. Further research is therefore needed to enable clinicians and developers to embrace the idea that the human interaction assessment have to be performed in the field, instead of only in the lab, and use a robust scientific approach. This will reduce the uncertainty about the POC device use and will enhance the product design.

In addition, there is a need to explore and diffuse new methods to assess, both implicitly and explicitly, the reaction of users (e.g. patients, clinicians) to such devices. This will also increase the ability to detect unmet needs, thus identifying potential new technical solutions for the healthcare market as well as informing current designs. 


\section{Key issues}

- Clinicians are used to assuming that any device available on the market is both usable and safe;

- Studies report the need for human factors and ergonomics methods to thoroughly explore the use and safety of POC;

- Currently, only a minimal set of usability studies in the field are carried out on POC devices;

- Usability metrics are only partially assessed through qualitative methods and do not generally use validated scales;

- Acceptance of POC devices is usually assessed as "the number of patients/clinicians who accept using the tool" but most studies do not also consider the other key factors that contribute to acceptance;

- Expectations and reactions to the device in use are only superficially included in the POC device studies;

- Interaction and acceptance analyses are performed in the medical field often without referencing the methods used and/or the research related to the variables under assessment;

- The scales applied in the human factor assessments are often 'homemade' and insufficiently developed, tested and reported. This reduces the reproducibility of the study and limits the scope for comparative analyses;

- Human factors and ergonomics included in clinical studies may act as a catalyst to the future development of POC devices and to the modelling and understanding of both the current and future use of POC devices in the medical field;

- Human factors/ergonomics experts have to embrace the concept of point of care culture by supporting clinicians and manufacturers to widen their perspective about the factors involved in the interaction with devices.

\section{Financial and competing interests disclosure}

This research was supported by the National Institute for Health Research (NIHR) Diagnostic Evidence Co-operative London at Imperial College Healthcare NHS Trust. The authors have no other relevant affiliations or financial involvement with any organization or entity with a financial interest in or financial conflict with the subject matter or materials discussed in the manuscript apart from those disclosed. 


\section{References}

\section{Papers of special note have been highlighted as either of interest $(*)$ or of considerable interest $(* *)$ to readers.}

1. Lippi G, Mattiuzzi C, Cervellin G. Point of care troponin testing: Rules and regulations. Journal of Electrocardiology 2013: 46;(6): 727-728.

2. Nichols JH. Quality in point-of-care testing. Expert Review of Molecular Diagnostics 2003: 3;(5): 563-572.

3. Pauly S, Fisher P, Jacobs E, Levine A, Rincon H. Regulations and point-of-care testing. Laboratory Medicine 1997: 28;(8): 504-508.

4. Howick J, Cals JWL, Jones C et al. Current and future use of point-of-care tests in primary care: an international survey in Australia, Belgium, The Netherlands, the UK and the USA. BMJ Open 2014: 4;(8): 1-9.

* The article provides a large survey across different countries on advantages, use and future use of POC devices.

5. DuBois JA. The role of POCT and rapid testing. Medical Laboratory Observer; 2013: 45;(9): 18.

6. Jones $\mathrm{C}$, Howick J, Roberts $\mathrm{N}$ et al. Primary care clinicians' attitudes towards point-of-care blood testing: a systematic review of qualitative studies. BMC Family Practice 2013: 14;(1): 117.

** The article provides a comprehensive review on advantages, issues and concerns related to the use of POC devices.

7. Laurence CO, Gialamas A, Bubner T et al. Patient satisfaction with point-of-care testing in general practice. 2010.

8. Gialamas A, Yelland L, Ryan P et al. Does point-of-care testing lead to the same or better adherence to medication? A randomised controlled trial: the PoCT in General Practice Trial. Med J Aust 2009: 191;(9): 487-491.

9. Hurley A, Dnsc RN, Bane A etal. Nurses' Satisfaction With Medication Administration Point-ofCare Technology. J Nurs Adm 2007: 37;(7/8): 343-349.

10. Jackman J, Uy M, Hsieh X-H et al. Minding the Gap: An Approach to Determine Critical Drivers in the Development of Point-of-Care Diagnostics. Point care 2012: 11;(2): 130-139.

11. Gurses AP, Ozok AA, Pronovost PJ. Time to accelerate integration of human factors and ergonomics in patient safety. BMJ Quality \& Safety 2011: 21;(4): 347-351.

12. Russ AL, Fairbanks RJ, Karsh B-T, Militello LG, Saleem JJ, Wears RL. The science of human factors: separating fact from fiction. BMJ Quality \& Safety 2013: 1-7.

13. ISO. ISO EN 62366:2008 Medical devices - Application of usability engineering to medical devices. CEN; Brussels, BE:2008.

14. ISO. EN ISO 14971:2012 Medical devices - Application of risk management to medical devices. CEN; Brussels, BE:2012.

15. Horsky J, Zhang J, Patel VL. To err is not entirely human: Complex technology and user cognition. Journal of Biomedical Informatics 2005: 38;(4): 264-266.

Medicines and Healthcare products Regulatory Agency. Medical devices - adverse incidents reported to MHRA in 2011 and 2012. MHRA; London, UK:2014.

17. ExpertSOLUTIONS S. Stericycle Recall Index Q3 2014. Stericycle ExpertSOLUTIONS Indianapolis, IN:2014.

18. Meier FA, Jones BA. Point-of-Care Testing Error: Sources and Amplifiers, Taxonomy, Prevention Strategies, and Detection Monitors. Archives of Pathology \& Laboratory Medicine 2005: 129;(10): 1262-1267.

19. Velez D, Shanblatt M. Taxonomy of current medical devices for POCT applications and the potential acceptance of Bluetooth technology for secure interoperable applications. In: $e$-Health Networking Applications and Services (Healthcom), 2011 13th IEEE International Conference on.2011. 
20. Vincent C, Blandford A. Designing for Safety and Usability: User-Centered Techniques in Medical Device Design Practice. Proceedings of the Human Factors and Ergonomics Society Annual Meeting 2011: 55;(1): 793-797.

21. Carayon P, Wetterneck TB, Rivera-Rodriguez AJ et al. Human factors systems approach to healthcare quality and patient safety. Applied Ergonomics 2014: 45;(1): 14-25.

22. Cohen MR. Why error reporting systems should be voluntary: They provide better information for reducing errors. British Medical Journal 2000: 320;(7237): 728-729.

23. Senders JW. Chapter 9: Medical devices, medical errors, and medical accidents. In: Human error in medicine. Bogner, MS. Lawrence Erlbaum Associa; Hillsdale, NJ:1994.

24. Gawron VJ, Drury CG, Fairbanks RJ, Berger RC. Medical Error and Human Factors Engineering: Where Are We Now? American Journal of Medical Quality 2006: 21;(1): 57-67.

25. Kirwan B. Human Reliability Assessment. In: Evaluation of Human Work. Wilson JR, Sharples S. CRC Press; Boca Raton, FL:2015.

26. Hendrick HW, Kleiner BM. Macroergonomics: An Introduction to Work System Design. Human Factors and Ergonomics Society: Santa Monica, CA, 2001.

27. Hignett $\mathrm{S}$, Carayon $\mathrm{P}$, Buckle $\mathrm{P}$, Catchpole K. State of science: human factors and ergonomics in healthcare. Ergonomics 2013: 56;(10): 1491-1503.

28. Ward J, Buckle P, John Clarkson P. Designing packaging to support the safe use of medicines at home. Applied Ergonomics 2010: 41;(5): 682-694.

29. Buckle P, Clarkson PJ, Coleman R, Bound J, Ward J, Brown J. Systems mapping workshops and their role in understanding medication errors in healthcare. Applied Ergonomics 2010: 41;(5): 645-656.

30. Jun GT, Ward J, Morris Z, Clarkson J. Health care process modelling: which method when? International Journal for Quality in Health Care 2009:21;(3): 214-224.

31. Jun GT, Ward J, Clarkson PJ. Systems modelling approaches to the design of safe healthcare delivery: ease of use and usefulness perceived by healthcare workers. Ergonomics 2010: 53;(7): 829-847.

32. Jiancaro T, Jamieson GA, Mihailidis A, Twenty Years of Cognitive Work Analysis in Health Care: A Scoping Review. Journal of Cognitive Engineering and Decision Making 2014: 8;(1): 322.

33. Lim RHM, Anderson JE, Buckle PW. Work Domain Analysis for understanding medication safety in care homes in England: an exploratory study. Ergonomics 2015: 1-28.

34. Lane R, Stanton NA, Harrison D. Applying hierarchical task analysis to medication administration errors. Applied Ergonomics 2006: 37;(5): 669-679.

35. Carayon P. Human factors of complex sociotechnical systems. Applied Ergonomics 2006: 37;(4): 525-535.

36. Zink KJ. Ergonomics in the past and the future: from a German perspective to an international one. Ergonomics 2000: 43;(7): 920-930.

37. Dillon A. Group Dynamics Meet Cognition: Combining Socio-Technical Concepts and Usability Engineering in the Design of Information Systems. In: The New SocioTech. Coakes E, Willis D, Lloyd-Jones R. Springer London:2000.

38. Carayon P, Karsh B-T, Gurses AP et al. Macroergonomics in Healthcare Quality and Patient Safety. Review of human factors and ergonomics 2013: 8;(1): 4-54.

39. Wilson JR, Sharples S. Methods in the understanding of Human Factors. CRC Press; Boca Raton, FL:2015.

40. Borsci S, Kurosu M, Federici S, Mele ML. Computer systems experiences of users with and without disabilities: an evaluation guide for professionals - Ch7: How you can set up and perform an interaction evaluation rules and methods. CRC Press: Boca Raton, FL, 2013.

41. Federici S, Borsci S. Usability evaluation: models, methods, and applications. In: International Encyclopedia of Rehabilitation. Stone JH, Blouin M. http://cirrie.buffalo.edu/encyclopedia/en/article/277/:2010.

\section{** This chapter provides an overall perspective on human factors and ergonomics assessment methods}


42. ISO. ISO 9241-11:1998 Ergonomic requirements for office work with visual display terminals. CEN; Brussels, BE:1998.

43. ISO. ISO 9241-210:2010 Ergonomics of human-system interaction -- Part 210: Human-centred design for interactive systems. CEN; Brussels, BE:2010.

44. Venkatesh V, Davis FD. A Theoretical Extension of the Technology Acceptance Model: Four Longitudinal Field Studies. Management Science 2000: 46;(2): 186-204.

45. Davis FD. Perceived Usefulness, Perceived Ease of Use, and User Acceptance of Information Technology. MIS Quarterly 1989: 13;(3): 319-340.

46. Lankton N, McKnight DH, Thatcher JB. Incorporating trust-in-technology into Expectation Disconfirmation Theory. The Journal of Strategic Information Systems 2014: 23;(2): 128-145.

47. Salanitri D, Hare C, Borsci S, Lawson G, Sharples S, Waterfield B. Relationship Between Trust and Usability in Virtual Environments: An Ongoing Study. In: Human-Computer Interaction: Design and Evaluation. Kurosu M. Springer International Publishing:2015.

48. Borsci S, Kuljis J, Barnett J, Pecchia L. Beyond the User Preferences: Aligning the Prototype Design to the Users' Expectations. Human Factors and Ergonomics in Manufacturing \& Service Industries 2014: n/a-n/a.

49. Lee S, Koubek RJ. Understanding user preferences based on usability and aesthetics before and after actual use. Interacting with Computers 2010: 22;(6): 530-543.

50. Lee S, Koubek RJ. The Impact of Cognitive Style on User Preference Based on Usability and Aesthetics for Computer-Based Systems. International Journal of Human-Computer Interaction 2011: 27;(11): 1083-1114.

51. Sharples S, Cobbs S. Methods for Collecting and Observing Participants Responses. In: Evaluation of Human Work. Wilson JR, Sharples S. CRC Press; Boca Raton, FL:2015.

** This chapter provides an overall perspective on human factors and ergonomics methods

52. Money A, Barnett J, Kuljis J, Craven M, Martin J, Young T. The role of the user within the medical device design and development process: medical device manufacturers' perspectives. BMC Med Inform Decis Mak 2011: 11;(1): 1-12.

53. Brooke J. SUS: a "quick and dirty" usability scale. In: Usability Evaluation in Industry. Jordan PW, Thomas B, Weerdmeester BA, McClelland AL. Taylor \& Francis; London:1996.

* This article presents and discusses one of the most applied scale to assess satisfaction

54. Hassenzahl M. Hedonic, Emotional, and Experiential Perspectives on Product Quality. In: Encyclopedia of Human Computer Interaction. Ghaoui C. Information Science Reference; Hershey, PA:2006.

55. Hart SG, Staveland LE. Development of NASA-TLX (Task Load Index): Results of Empirical and Theoretical Research. In: Advances in Psychology. Peter AH, Najmedin M. NorthHolland:1988.

56. Junker R, Schlebusch H, Luppa PB. Point-of-Care Testing in Hospitals and Primary Care. Deutsches Ârzteblatt International 2010: 107;(33): 561-567.

57. National Institutes of Health. FACT SHEET - Point-of-Care Diagnostic Testing. In: Research Portfolio Online Reporting Tools. NIH RePORT; USA:2010.

58. Kushniruk AW, Triola MM, Borycki EM, Stein B, Kannry JL. Technology induced error and usability: The relationship between usability problems and prescription errors when using a handheld application. International Journal of Medical Informatics 2005: 74;(7-8): 519-526.

59. Stricklin MLV, Struk CM. Point of Care Technology: A Sociotechnical Approach to Home Health Implementation. Methods of Information in Medicine 2003: 42;(4): 463-470.

60. Cals JWL, Chappin FHF, Hopstaken RM et al. C-reactive protein point-of-care testing for lower respiratory tract infections: a qualitative evaluation of experiences by GPs. Family Practice 2010: 27;(2): 212-218.

61. Wood F, Brookes-Howell L, Hood K et al. A multi-country qualitative study of clinicians' and patients' views on point of care tests for lower respiratory tract infection. Family Practice 2011: 28;(6): 661-669. 
62. Agustí C, Fernàndez-López L, Mascort J et al. Acceptability of rapid HIV diagnosis technology among primary healthcare practitioners in Spain. AIDS Care - Psychological and Socio-Medical Aspects of AIDS/HIV 2013: 25;(5): 544-549.

63. Bello FA, Ogunbode OO, Adesina OA, Olayemi O, Awonuga OM, Adewole IF. Acceptability of counselling and testing for HIV infection in women in labour at the University College Hospital, Ibadan, Nigeria. African Health Sciences 2011: 11;(1): 30-35.

64. Iqbal S, De Souza LR, Yudin MH. Acceptability, predictors and attitudes of Canadian women in labour toward point-of-care HIV testing at a single labour and delivery unit. The Canadian Journal of Infectious Diseases \& Medical Microbiology 2014: 25;(4): 201-206.

65. Schalkwyk J, Amiri N, Lalji S, Gardella C, Wald A, Money D. Acceptance of a rapid herpes test in labour: survey of attitudes of patients and health care providers. Journal of obstetrics and gynaecology Canada 2008: 30;(9): 776-780.

66. Cals J, van Weert H. Point-of-care tests in general practice: Hope or hype? European Journal of General Practice 2013: 19;(4): 251-256.

67. FDA U. Draft Guidance for Industry and Food and Drug Administration Staff-Applying Human Factors and Usability Engineering to Optimize Medical Device Design. US FDA; Silver Spring, MD, USA:2011.

68. Laurence C, Gialamas A, Yelland L et al. A pragmatic cluster randomised controlled trial to evaluate the safety, clinical effectiveness, cost effectiveness and satisfaction with point of care testing in a general practice setting - rationale, design and baseline characteristics. Trials 2008 : 9;(1): 50 .

69. Butler CC, Simpson S, Wood F. General practitioners' perceptions of introducing near-patient testing for common infections into routine primary care: A qualitative study. Scandinavian Journal of Primary Health Care 2008: 26;(1): 17-21.

70. Bulterys M, Jamieson DJ, O'Sullivan MJ et al. Rapid HIV-1 testing during labor: A multicenter study. Journal of the American Medical Association 2004: 292;(2): 219-223.

71. Heller T, Kunthea S, Bunthoeun E et al. Point-of-care hiv testing at antenatal care and maternity sites: Experience in Battambang Province, Cambodia. International Journal of STD and AIDS 2011: 22;(12): 742-747.

72. Agustí C, Fernàndez-López L, Mascort J et al. Attitudes to rapid HIV testing among Spanish General Practitioners. HIV Medicine 2013:14;(SUPPL.3): 53-56.

73. Conners EE, Hagedorn HJ, Butler JN et al. Evaluating the implementation of nurse-initiated HIV rapid testing in three Veterans Health Administration substance use disorder clinics. International Journal of STD \& AIDS 2012: 23;(11): 799-805.

74. Chen JC, Goetz MB, Feld JE et al. A provider participatory implementation model for HIV testing in an ED. American Journal of Emergency Medicine 2011: 29;(4): 418-426.

75. Merchant RC, Clark MA, Seage GR, Mayer KH, Degruttola VG, Becker BM. Emergency department patient perceptions and preferences on opt-in rapid HIV screening program components. AIDS Care - Psychological and Socio-Medical Aspects of AIDS/HIV 2009: 21;(4): 490-500.

76. Wurcel A, Zaman T, Zhen S, Stone D. Acceptance of HIV antibody testing among inpatients and outpatients at a public health hospital: A study of rapid versus standard testing. AIDS Patient Care and STDs 2005: 19;(8): 499-505.

77. Mayega RW, Guwatudde D, Makumbi FE et al. Comparison of fasting plasma glucose and haemoglobin A1c point-of-care tests in screening for diabetes and abnormal glucose regulation in a rural low income setting. Diabetes Research and Clinical Practice 2014: 104;(1): 112-120.

78. Weigl BH, Zwisler G, Peck R, Abu-Haydar E. Rapid screening test for gestational diabetes Public health need, market requirement, initial product design, and experimental results. In: Proceedings of SPIE - The International Society for Optical Engineering.2013.

79. Bienek DR, Perez NM. Diagnostic accuracy of a point-of-care blood typing kit conducted by potential end users. Military medicine 2013: 178;(5): 588-592.

80. Shephard MDS, Spaeth B, Mazzachi BC et al. Design, implementation and initial assessment of the Northern Territory Point-of-Care Testing Program. Australian Journal of Rural Health 2012: 20;(1): 16-21. 
81. Loten C, Attia J, Hullick C, Marley J, McElduff P. Point of care troponin decreases time in the emergency department for patients with possible acute coronary syndrome: a randomised controlled trial. Emerg Med J 2010: 27;(3): 194-198.

82. Kong M, Lim T, Ng H, Chan Y, Lee L. Feasibility, cost-effectiveness and patients' acceptance of point-of-care INR testing in a hospital-based anticoagulation clinic. Ann Hematol 2008: 87;(11): 905-910.

83. Seto E, Chagpar A, Roach C, MacDonald A. Usability evaluations as part of the procurement process: Case study of hospital point of care carts. In: Proceedings of the Human Factors and Ergonomics Society.2006.

84. Ferris DG, Dickman ED, Litaker MS, Smith KM, Allmond LM, Arrington TL. Patient acceptance of fluorescent and reflective spectroscopy as a replacement test for the pap smear. Journal of Lower Genital Tract Disease 2003: 7;(4): 294-298.

85. Kost GJ. Preventing Medical Errors in Point-of-Care Testing. Archives of Pathology \& Laboratory Medicine 2001: 125;(10): 1307-1315.

86. Lewis JR. Introduction to the Special Issue on Usability and User Experience:Psychometrics. International Journal of Human-Computer Interaction 2015: 31;(8): 481-483.

87. Kost GJ, Ferguson WJ, Kost LE. Principles of point of care culture, the spatial care path ${ }^{\mathrm{TM}}$, and enabling community and global resilience. The Electronic Journal of the International Federation of Clinical Chemistry 2014: 25: 4-23.

** This article presents and discusses the concept of point of care culture

88. Kost GJ, Zhou Y, Katip P. Point of care culture survey. In: Global Point of Care: Strategies for Disasters, Emergencies, and Public Health Resilience. Kost, GJ, Curtis, CM. American Association for Clinical Chemistry Press; Washington, D.C.:2015.

89. Curtis CM, Louie RF, Kost GJ. The current and future status of point of care in national disaster caches. In: Global Point of Care: Strategies for Disasters, Emergencies, and Public Health Resilience. Kost, GJ, Curtis, CM. American Association for Clinical Chemistry Press Washington, D.C.:2015.

90. Kost GJ, Louie RF, Curtis CM, Ferguson WJ, Troung A-T. The logic web of future global resilience. In: Global Point of Care: Strategies for Disasters, Emergencies, and Public Health Resilience. Kost, GJ, Curtis, CM. American Association for Clinical Chemistry Press; Washington, D.C.:2015,

91. Kost GJ, Louie RF, Truong A-T, Curtis CM. A global perspective of needs assessment for rapid decision making in pandemics, complex emergencies, and disasters. In: Global Point of Care: Strategies for Disasters, Emergencies, and Public Health Resilience. Kost, GJ, Curtis, CM. American Association for Clinical Chemistry Press Washington, D.C.:2015.

92. Kost GJ, Zhou Y, Katip P. Understanding point of care culture improves resiliency and standards of care in resource-limited countries. In: Global Point of Care: Strategies for Disasters, Emergencies, and Public Health Resilience. Kost, GJ, Curtis, CM. American Association for Clinical Chemistry Press; Washington, D.C.:2015.

93. Dhawan AP, Heetderks WJ, Pavel M et al. Current and Future Challenges in Point-of-Care Technologies: A Paradigm-Shift in Affordable Global Healthcare with Personalized and Preventive Medicine. IEEE Journal of Translational Engineering in Health and Medicine 2015: 3: n.a.

94. Weiser M. The computer for the $21^{\text {st }}$ century. SIGMOBILE Mob. Comput. Commun. Rev. 1999: 3;(3): 3-11.

95. Jordan P. Designing Pleasurable Products: An Introduction to the New Human Factors. Taylor \& Francis: London, 2002. 


\begin{tabular}{|c|c|c|}
\hline $\begin{array}{c}\text { Target } \\
\text { measure }\end{array}$ & Key variables to meet the target & Commonplace methodology \\
\hline $\begin{array}{l}\text { Acceptance } \\
\text { [see: } 44,45]\end{array}$ & $\begin{array}{ll}- & \text { Perceived usefulness } \\
- & \text { Easiness of use } \\
\text { - } & \text { Attitudes }\end{array}$ & Standardised questionnaire \\
\hline $\begin{array}{l}\text { Usability [see: } \\
13,41,42]\end{array}$ & $\begin{array}{ll}- & \text { Performance (errors and time) } \\
- & \text { Satisfaction }\end{array}$ & $\begin{array}{ll}- & \text { Direct Observation } \\
\text { - } & \text { Post use data gathering (video, } \\
& \text { notes, diary etc.) } \\
\text { - } & \text { Standardised scale } \\
\end{array}$ \\
\hline $\begin{array}{l}\text { Experience } \\
\text { [see: } 20,40,53]\end{array}$ & $\begin{array}{l}\text { - } \quad \text { Performance through the time } \\
\text { - } \quad \text { Satisfaction through the time } \\
\text { - } \quad \text { Emotional and physiological reactions }\end{array}$ & $\begin{array}{ll}- & \text { Direct Observation } \\
- & \text { Post use data gathering (video, } \\
& \text { notes, diary etc.) } \\
\text { - } & \text { Standardised scale }\end{array}$ \\
\hline $\begin{array}{l}\text { Expectations } \\
\text { [see: } 49,50,53]\end{array}$ & - $\quad$ Preference before and after the use & Tested scales \\
\hline $\begin{array}{l}\text { Reaction } \\
\text { [see: } 39,54,55]\end{array}$ & $\begin{array}{l}\text { - Physiological reactions such as stress, cognitive } \\
\text { workload, attention and attractiveness }\end{array}$ & $\begin{array}{l}\text { Biofeedback instruments, } \\
\text { standardised scales }\end{array}$ \\
\hline
\end{tabular}

Table 1. Target measure of interaction assessment with technology, minimal set of variables to achieve the target, and commonplace methodology for the assessment.

\begin{tabular}{|c|c|c|c|c|}
\hline \multirow[t]{2}{*}{ Study } & \multirow{2}{*}{$\begin{array}{l}\text { Participants } \\
\text { n. and types }\end{array}$} & \multicolumn{2}{|c|}{ HFE related aspects } & \multirow[t]{2}{*}{ Assessment Methods } \\
\hline & & Interaction aspect & Observed HFE variables & \\
\hline $\begin{array}{l}\text { Agustí et al. } \\
2013 \text { [72] } \\
\text { Agustí et al. } \\
2013 \text { [62] }\end{array}$ & $\begin{array}{l}1308 \\
\text { clinicians }\end{array}$ & - Acceptance & $\begin{array}{l}\text { - Acceptance rate } \\
\text { - Attitudes } \\
\text { - Barriers of use }\end{array}$ & - Questionnaire \\
\hline \multicolumn{5}{|c|}{ Note: Authors used a similar set of data and method to look mainly at attitudes toward POC [72] or at acceptability of POC [62] } \\
\hline $\begin{array}{l}\text { Bello et al. } 2011 \\
\text { [63] }\end{array}$ & 104 patients & Acceptance & $\begin{array}{l}\text { Acceptance rate } \\
\text { Reasons }\end{array}$ & $\begin{array}{l}\text { - Interview } \\
\text { - Questionnaire }\end{array}$ \\
\hline $\begin{array}{l}\text { Bienek et al. } \\
2013 \text { [79] }\end{array}$ & 377 patients & $\begin{array}{l}\text { - Usability and } \\
\text { experience }\end{array}$ & $\begin{array}{l}\text { - Errors in use } \\
\text { - Results interpretation } \\
\text { - People skills impact }\end{array}$ & $\begin{array}{l}\text { - Observation } \\
\text { - Questionnaire }\end{array}$ \\
\hline $\begin{array}{l}\text { Cals et al. } 2010 \\
{[60]}\end{array}$ & & Usability and & $\begin{array}{l}\text { - Perceived experience } \\
\text { - Attitudes }\end{array}$ & - Interview \\
\hline $\begin{array}{l}\text { Chen et al. } 2011 \\
\text { [74] }\end{array}$ & 121 patients & $\begin{array}{l}\text { bility and } \\
\text { erience }\end{array}$ & $\begin{array}{l}\text { - Easiness of use } \\
\text { - Satisfaction } \\
\text { - Facilitators of use } \\
\end{array}$ & $\begin{array}{ll}\text { - Interview } \\
\text { - Questionnaire }\end{array}$ \\
\hline $\begin{array}{l}\text { Conners et al. } \\
2012 \text { [73] }\end{array}$ & $\begin{array}{l}35 \text { patients } \\
3 \text { clinicians }\end{array}$ & Acceptance & $\begin{array}{l}\text { - Experienced barriers } \\
\text { - Attitudes }\end{array}$ & $\begin{array}{ll}\text { - } & \text { Interview } \\
\text { - } & \text { Questionnaire }\end{array}$ \\
\hline $\begin{array}{l}\text { Ferr } \\
{[84]}\end{array}$ & patients & $\begin{array}{l}\text { - } \text { Acceptance } \\
\text { - Expectations and } \\
\text { reactions }\end{array}$ & $\begin{array}{l}\text { - Acceptance rate } \\
\text { - Reasons } \\
\text { - Barriers of use } \\
\text { - Preferences in use }\end{array}$ & $\begin{array}{l}\text { - Questionnaire } \\
\text { - } \text { Comparison of devices } \\
\text { solutions }\end{array}$ \\
\hline $\begin{array}{l}\text { Iqbal et al. } 2014 \\
\text { [64] }\end{array}$ & 92 patients & - Acceptance & $\begin{array}{l}\text { - Acceptance rate } \\
\text { - Reasons } \\
\text { - Concerns before the } \\
\text { test/attitudes }\end{array}$ & - Questionnaire \\
\hline $\begin{array}{l}\text { Kong et al. } 2008 \\
\text { [82] }\end{array}$ & 230 patients & - Acceptance & $\begin{array}{l}\text { - Acceptance rate } \\
\text { - Satisfaction } \\
\text { - Usefulness }\end{array}$ & $\begin{array}{l}\text { Interview and } \\
\text { Questionnaire }\end{array}$ \\
\hline Kost $2001[85]$ & 212 clinicians & $\begin{array}{l}\text { - Usability and } \\
\text { experience }\end{array}$ & $\begin{array}{l}\text { - Performance in use } \\
\text { - Perceived safety } \\
\text { - Features of POC }\end{array}$ & - Questionnaire \\
\hline $\begin{array}{l}\text { Laurence et al. } \\
2008 \text { [68] }\end{array}$ & $\begin{array}{l}115 \text { patients } \\
58 \text { clinicians }\end{array}$ & $\begin{array}{l}\text { - Usability and } \\
\text { experience }\end{array}$ & $\begin{array}{l}\text { - Performance } \\
\text { - Perceived Safety } \\
\text { - Attitudes toward } \\
\text { - Satisfaction }\end{array}$ & $\begin{array}{l}\text { - } \text { Clinicians notes } \\
\text { - Questionnaire (through } \\
\text { a period of time) }\end{array}$ \\
\hline
\end{tabular}




\begin{tabular}{|c|c|c|c|c|}
\hline $\begin{array}{l}\text { Laurence et al. } \\
2010 \text { [7] }\end{array}$ & 4968 patients & $\begin{array}{l}\text { - Usability and } \\
\text { experience }\end{array}$ & - Satisfaction & - Questionnaire \\
\hline $\begin{array}{l}\text { Mayega et al. } \\
2014 \text { [77] }\end{array}$ & $\begin{array}{l}795 \text { patients } \\
24 \text { clinicians }\end{array}$ & $\begin{array}{l}\text { - Usability and } \\
\text { experience }\end{array}$ & $\begin{array}{l}\text { - Easiness of use } \\
\text { - Perceived use } \\
\text { - Reversible and } \\
\text { irreversible mistakes } \\
\text { - Errors in use }\end{array}$ & - Interview \\
\hline $\begin{array}{l}\text { Merchant et al. } \\
2009 \text { [75] }\end{array}$ & 2155 patients & $\begin{array}{l}\text { - Usability and } \\
\text { experience } \\
\text { - Expectations and } \\
\text { reactions }\end{array}$ & $\begin{array}{l}\text { - Preferences of use } \\
\text { - Perceived usefulness } \\
\text { - Perceived } \\
\text { performance }\end{array}$ & - Questionnaire \\
\hline $\begin{array}{l}\text { Schalkwyk et al. } \\
2008 \text { [65] }\end{array}$ & $\begin{array}{l}226 \text { patients } \\
51 \text { clinicians }\end{array}$ & - Acceptance & $\begin{array}{l}\text { - Attitudes toward a } \\
\text { new POC device }\end{array}$ & - Questionnaire \\
\hline $\begin{array}{l}\text { Seto et al. } 2006 \\
\text { [83] }\end{array}$ & 4 clinicians & $\begin{array}{l}\text { - Usability and } \\
\text { experience }\end{array}$ & $\begin{array}{l}\text { - Performance } \\
\text { - Satisfaction }\end{array}$ & $\begin{array}{l}\text { - Observation } \\
\text { - } \text { Verbal protoc } \\
\text { - } \text { Questionnaire }\end{array}$ \\
\hline $\begin{array}{l}\text { Shephard et al. } \\
2012 \text { [80] }\end{array}$ & 161 clinicians & $\begin{array}{l}\text { - Usability and } \\
\text { experience }\end{array}$ & $\begin{array}{l}\text { - Performance } \\
\text { - Satisfaction }\end{array}$ & $\begin{array}{l}\text { - Observation } \\
\text { - Questionnaire }\end{array}$ \\
\hline $\begin{array}{l}\text { Wurcel et al. } \\
2005[76]\end{array}$ & 203 patients & - Acceptance & $\begin{array}{l}\text { - Acceptance rate } \\
\text { - Reasons }\end{array}$ & $\begin{array}{l}\text { Interview } \\
\text { Questionnaire }\end{array}$ \\
\hline
\end{tabular}

Table 2. Summary of selected outcomes.

\begin{tabular}{|c|c|c|c|}
\hline \multirow[t]{2}{*}{ Study } & \multicolumn{2}{|c|}{ HFE related aspects } & \multirow{2}{*}{$\begin{array}{l}\text { Unexplored } \\
\text { variables }\end{array}$} \\
\hline & Interaction aspect & Observed HFE variables & \\
\hline Agustí et al. 2013 [72] & & - Acceptance rate & - Perceived \\
\hline Agustí et al. 2013 [62] & - Acceptance & $\begin{array}{l}\text { - Attitudes } \\
\text { - Barriers of use }\end{array}$ & $\begin{array}{l}\text { usefulness } \\
\text { - } \text { Easiness of use }\end{array}$ \\
\hline Bello et al. 2011 [63] & - Acceptance & & $\begin{array}{ll}\text { - } & \text { Perceived } \\
& \text { usefulness } \\
\text { - } & \text { Easiness of use } \\
\text { - } & \text { Attitudes toward } \\
& \text { test } \\
\end{array}$ \\
\hline Bienek et al. 2013 [79] & - Usability and experience & $\begin{array}{l}\text { - Errors in use } \\
\text { - Results interpretation } \\
\text { - People skills impact }\end{array}$ & - Satisfaction \\
\hline Cals et al. 2010 [60] & - Usability and experience & $\begin{array}{l}\text { - Perceived experience } \\
\text { - Attitudes }\end{array}$ & $\begin{array}{l}\text { - Performance } \\
\text { - Satisfaction } \\
\end{array}$ \\
\hline Che & & $\begin{array}{l}\text { - Easiness of use } \\
\text { - Satisfaction } \\
\text { - Facilitators of use }\end{array}$ & Performance \\
\hline $\begin{array}{l}\text { Cont } \\
{[73]}\end{array}$ & Acceptance & $\begin{array}{l}\text { - Experienced barriers } \\
\text { - Attitudes }\end{array}$ & - Performance \\
\hline $03[84]$ & $\begin{array}{l}\text { - Acceptance } \\
\text { - Expectations and } \\
\text { reactions }\end{array}$ & $\begin{array}{l}\text { - Acceptance rate } \\
\text { - Reasons } \\
\text { - Barriers of use } \\
\text { - Preferences in use }\end{array}$ & $\begin{array}{ll}\text { - } & \text { Perceived } \\
& \text { usefulness } \\
\text { - } & \text { Easiness of use } \\
\text { - } & \text { Attitudes toward } \\
& \text { test } \\
\end{array}$ \\
\hline Iqbal et al. 2014 [64] & - Acceptance & $\begin{array}{l}\text { - Acceptance rate } \\
\text { - Reasons } \\
\text { - Concerns before the } \\
\text { test/attitudes }\end{array}$ & $\begin{array}{ll}\text { - } & \text { Perceived } \\
& \text { usefulness } \\
\text { - } & \text { Easiness of use }\end{array}$ \\
\hline Kong et al. 2008 [82] & - Acceptance & $\begin{array}{l}\text { - Acceptance rate } \\
\text { - Satisfaction } \\
\text { - Usefulness }\end{array}$ & $\begin{array}{ll}\text { - } & \text { Perceived } \\
& \text { usefulness } \\
\text { - } & \text { Easiness of use }\end{array}$ \\
\hline Kost $2001[85]$ & - Usability and experience & $\begin{array}{l}\text { - Performance in use } \\
\text { - Perceived safety } \\
\text { - Features of POC }\end{array}$ & - Satisfaction \\
\hline $\begin{array}{l}\text { Laurence et al. } 2008 \\
\text { [68] }\end{array}$ & - Usability and experience & $\begin{array}{l}\text { - Performance } \\
\text { - Perceived Safety }\end{array}$ & -- \\
\hline
\end{tabular}




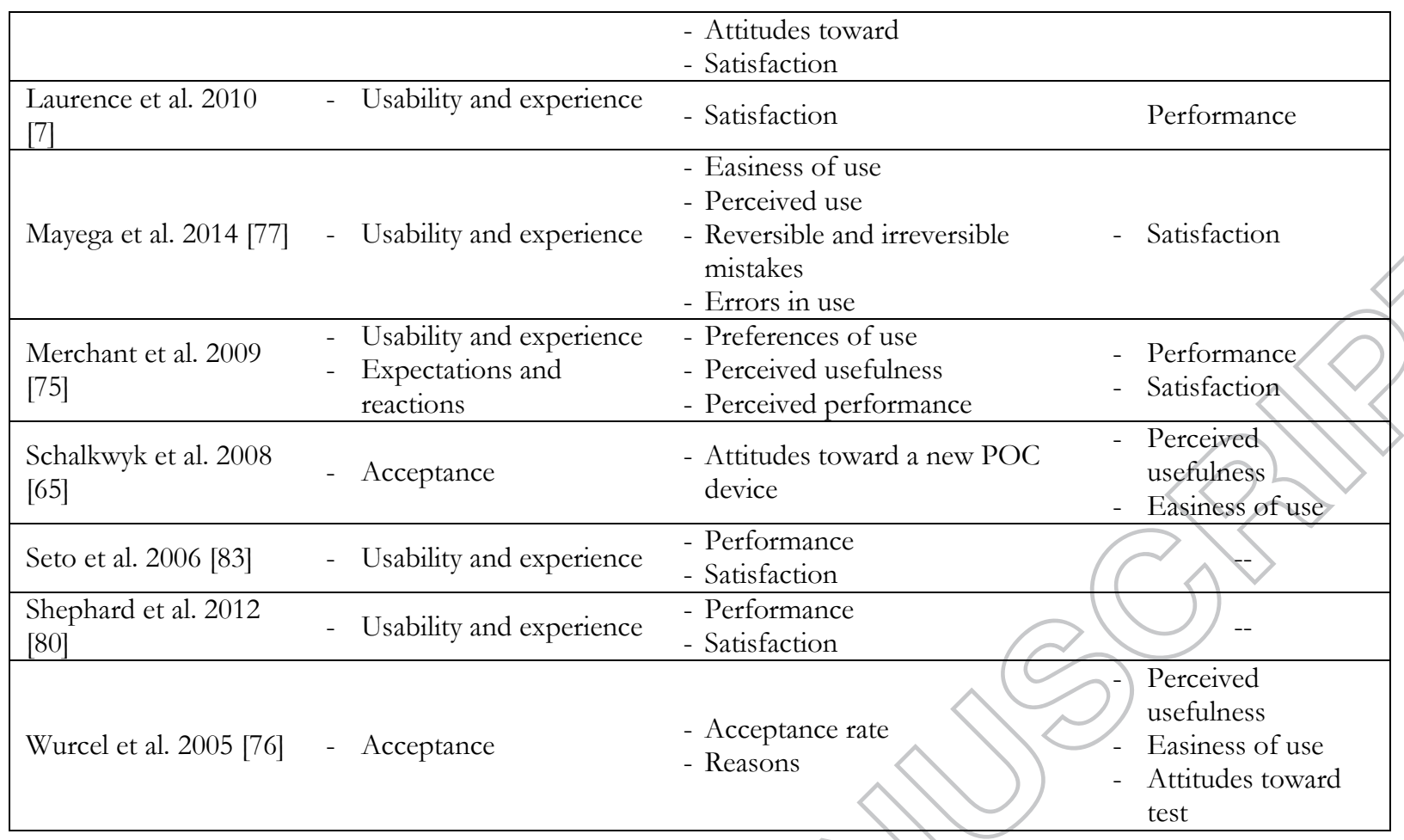

Table 3. Factors investigated and missing factors. Table shows expectations and reactions are rarely explored in clinical studies of POC devices; non-validated scales are usually utilised; acceptance, usability and experience variables are (at the very least) partially measured; several key HFE aspects are left unexplored in such studies.

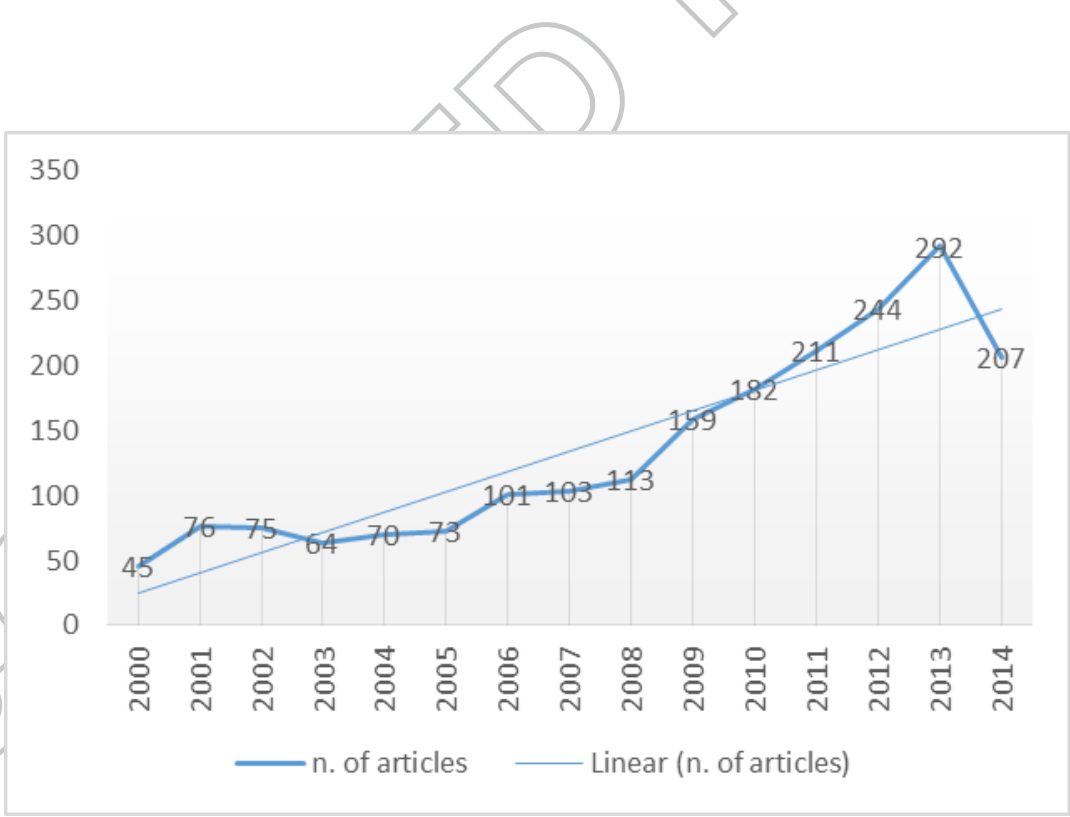

Figure 1. Number of journal and conference papers on POC devices from 2000 to 2014 in PUBMED. 


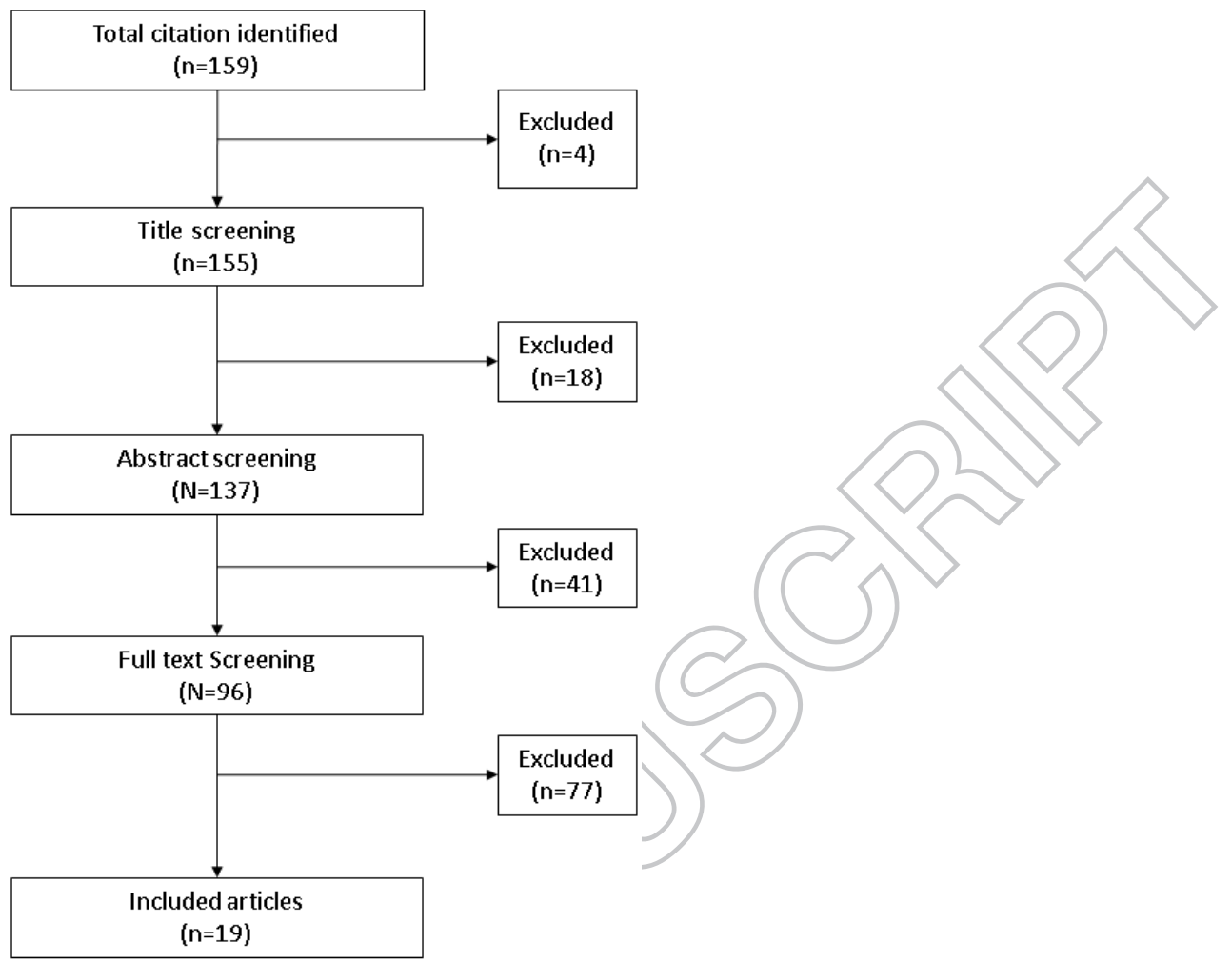

Figure 2. Flow diagram of study identification and selection

ANNEX 1. List of keywords related to point of care devices

Immediate, rapid, same time, near patient, portable, bedside, bed-side, POC testing, in vitro, in vitro diagnostics, POCT, point of care, Point-of-Care test, analysis, measure, systems, device, and technology.

Operators (AND/OR)

ANNEX 2. List of Human factors and ergonomics keywords

Human Factors, Ergonomics, usability engineering, Process mapping, Clinical pathways, Work domain analysis, HTA, Regulatory, Standards, Preference, Acceptance, safety, perceived safety, use error(s), user error(s), handling, satisfaction, usability, easiness of use, User Needs, User experience, people attitude, effectiveness in use, efficiency in use, context of use, intended use, Human Factors Engineering, Performance Technology; Use Studies; User Satisfaction (Information); quality control; User friendliness; Human engineering; Affective interaction.

Operators (AND/OR) 